\title{
Drug treatment of autism spectrum disorder and its comorbidities in children and adolescents ${ }^{\dagger}$
}

\author{
Paramala J. Santosh \& Jatinder Singh
}

\begin{abstract}
SUMMARY
Autism spectrum disorder (ASD) is a complex, multifactorial disorder, the prevalence of which is rising. Specific biomarkers are yet to be identified for the classic ASD phenotypes, so despite treatment advances, most interventions focus on the comorbid disorders of ASD and have little impact on the underlying pathogenesis of the disorder. This article describes drug treatments that target the core symptoms of ASD and its comorbid conditions in children and adolescents. Difficulties and challenges encountered when treating the most frequent comorbidities are discussed, with emphasis on the safety, tolerability and efficacy of medications. In view of its widespread use, complementary and alternative medicine is also described.
\end{abstract}

\section{LEARNING OBJECTIVES}

- Be aware that attention-deficit hyperactivity disorder (ADHD), anxiety disorders, depression and challenging behaviour (aggression and irritability) are frequently comorbid in ASD

- Understand that current drug treatments mainly aim to ameliorate such comorbidities without targeting the biological mechanisms that are responsible for the core symptoms of ASD

- Appreciate that for managing the core features of ASD, treatment programmes involving psychosocial, language and behavioural therapies remain the mainstay

\section{DECLARATION OF INTEREST}

P.J.S. is a co-inventor of the HealthTracker ${ }^{\mathrm{TM}}$ and a director of HealthTracker Ltd

In DSM-5 (American Psychiatric Association 2013), autism spectrum disorder (ASD) is now defined in a single category that previously included disorders that were considered separate such as pervasive developmental disorder (PDD), autistic disorder, Asperger syndrome, childhood disintegrative disorder and PDD not otherwise specified (PDD NOS), thus bringing all individuals with the same core symptoms into one designation.
This description converges with the National Institute for Health and Care Excellence (NICE) guidelines that describe autism as 'qualitative differences and impairments in reciprocal social interaction and social communication, combined with restricted interests and rigid and repetitive behaviours' (NICE 2011). In August 2013, an evidence-based guideline was published that summarised the different ways that healthcare professionals can manage, treat and support children and young people with ASD (NICE 2013). In terms of specific intervention for the core features of ASD, this guideline indicated that antipsychotics, antidepressants, anticonvulsants or exclusion diets (such as gluten- or casein-free diets) should not be used to manage the core features in children and young people with autism (NICE 2013: recommendation 1.3.2).

ASD is frequently associated with comorbid disorders such as intellectual disability, anxiety disorder, attention-deficit hyperactivity disorder (ADHD), depression, obsessive-compulsive disorder (OCD) and tic disorder. From an epidemiological perspective, a review of studies published since 2000 suggests that the incidence of ASD is about 66/10000, which equates to about 1/152 children, with males being affected more than females (at a ratio of 5:1) (Hill 2014).

Numerous studies have surmised that genetic predisposition and environmental factors might contribute to the pathophysiology of ASD (Sandin 2014), but the precise mechanisms remain unknown. Nevertheless, evidence suggests that the deficits in social communication and comorbid symptoms can be managed by focused behavioural interventions, medication, and medication coupled with behavioural interventions. The Autism Diagnostic Observation Schedule (ADOS) can quantify impaired social communication and other ASD symptomatology, but few clinical trials have used it and shown it to capture clinically meaningful change.

In this article, we explore the treatment of ASD and its comorbidities in children and adolescents.

\section{ARTICLE}

Paramala J. Santosh is a consultant child and adolescent psychiatrist and head of the Centre for Interventional Paediatric Psychopharmacology and Rare Diseases (CIPPRD), South London and Maudsley NHS Foundation Trust. He is also a Visiting Reader in developmental neuropsychiatry and psychopharmacology at the Institute of Psychiatry, Psychology \& Neuroscience, King's College London, and is an internationally recognised paediatric psychopharmacologist, with a career-long interest in ASD and its treatment in children and adolescents. Jatinder Singh is a research project officer with the CIPPRD in the Department of Child and Adolescent Psychiatry, Institute of Psychiatry, Psychology \& Neuroscience, King's College London.

Correspondence Dr Paramala J. Santosh, Centre for Interventional Paediatric Psychopharmacology and Rare Diseases (CIPPRD), 4 Windsor Walk, Denmark Hill, London SE5 8BB, UK. Email: paramala.1.santosh@kcl.ac.uk

†For a commentary see pp. 162-164, this issue. For a discussion of nondrug treatments (parent-mediated early interventions) see also pp. 146 and 147-150. 


\section{Treatment of ASD}

Despite the advances made in the treatment of ASD, the treatment trajectory is hindered because specific biomarkers have not yet been identified for the classic ASD phenotypes such as autistic disorder or Asperger syndrome, making it more difficult to target the core symptoms pharmacologically. Clinically, the established practice is to target the symptoms of the comorbid conditions associated with ASD, such as hyperactivity, irritability, psychosis, depression, aggression and repetitive behaviour. Of note, evidence suggests an increased propensity for psychiatric comorbidities (including neurodevelopmental disorders) in individuals with ASD, with $70 \%$ of children with ASD having at least one comorbid psychiatric disorder and $41 \%$ having two or more (Simonoff 2008).

Although there are varying amounts of empirical evidence for targeted pharmacological interventions, a number of different drug types are routinely used to treat comorbidities associated with ASD in children and adolescents. These include, but are not limited to, antidepressants, antipsychotics, anticonvulsants and stimulants. Despite the extremely common use of these medications, there is a dearth of evaluable information to address their efficacy in treating the core symptoms of ASD.

\section{Effective dosing with minimum side-effects}

An important challenge for clinicians is to identify treatments that have a suitably balanced safety and efficacy profile. The 'effective dose with minimum side-effects' is the dose that achieves acceptable improvement of symptoms with minimum adverse effects (Santosh 2014). Experience in the Centre for Interventional Paediatric Psychopharmacology and Rare Diseases (CIPPRD) has shown that medication should usually be initiated in small doses (typically an eighth to a sixth of the final anticipated dose), increasing about every five to six half-lives of the drug. In practice, for many drugs this is $3-7$ days, with certain exceptions. It may require 4-6 weeks of titration to identify the most effective dose with minimum side-effects (Santosh 2014). Fluoxetine liquid for anxiety or low mood, for example, might be initiated at $2-4 \mathrm{mg}$ once a day, increased by $2-4 \mathrm{mg}$ roughly every $7-8$ days because of its long half-life (1-4 days) (Altamura 1994) and increments made until the optimal dose is reached. This strategy needs to be discussed fully with the family and the patient. Feedback

a. HealthTracker ${ }^{\mathrm{TM}}$ is an internetbased platform developed using input from patients, parents and expert clinicians to monitor quality of life, symptoms and side-effects in paediatric care of chronic disorders. of treatment response in children seen by the CIPPRD. This will allow longitudinal capture of lifetime response to different treatments, helping us to understand the effective dose with minimum side-effects and maximum therapeutic efficacy, taking into account symptom response, side-effects, impairment and global functioning, for each treatment. This leads to treatmentresponse profiling of patients and treatment optimisation. The HealthTracker system has been used in clinical and research settings to monitor medication response and side-effects, for example the multicentre Suicidality: Treatment Occurring in Paediatrics (STOP) study (www.stop-study. com) that longitudinally followed children and adolescents (many of whom had ASD) on fluoxetine, aripiprazole and risperidone.

\section{Evaluation of the comorbidities in ASD}

When planning treatment regimens, an important first step is to exclude underlying medical conditions, as it is quite common for changes in behaviour in ASD to result from a previously unrecognised physical condition causing pain or discomfort (Santosh 2014), for example an unrecognised dental abscess. From clinical experience, a detailed physical examination ought to be undertaken in patients with ASD who have recently shown a change in behaviour. At the CIPPRD, identification and diagnoses of each co-occurring condition in ASD is made by confirming that the core symptoms of the cooccurring disorder are present (e.g. obsessions for diagnosing OCD); that symptoms reach 'thresholds' used in classificatory systems and are developmentally inappropriate; that symptoms are not 'double counted' (e.g. hyperactivity in ADHD and for hypomania); ensuring that each disorder produces additional impairment and checking that onset and course of the disorder are not indistinguishable and identical; and using multiple sources of information to ascertain the above criteria (Santosh 2014).

\section{Prescribing medications in ASD}

Owing to the cognitive rigidity and sensory problems encountered in patients with ASD, adapting prescribing to suit individuals is an important factor to consider in the management of treatment. This is described in more detail elsewhere (Santosh 2014). Individuals with ASD may not take a medication because of its odour, taste or formulation, so these factors should be carefully considered and managed for each patient.

An example of medication decision-making for comorbidity associated with ASD is presented 
in Table 1 and the evaluable evidence for this decision-making scheme can be deduced from the literature described in the following sections. Table 1 is intended to be used only as a general guide and is based on clinical experience (taking both efficacy and adverse events into account) and not on empirical evidence.

Holistic multimodal treatments are essential for the management of ASD. Treatment programmes such as psychosocial, language and behavioural therapies are not covered in this review, but it would be necessary to use them in conjunction with medication.

\section{Treatments for aggression and irritability}

Perhaps the most frequent and detrimental comorbidity associated with ASD is aggression. Typical and atypical antipsychotics have been used to treat it and the salient points will be described here.

\section{Risperidone}

In one randomised double-blind clinical trial (carried out by the Research Units of Paediatric Psychopharmacology (RUPP) Autism Network) involving 101 children with autistic disorder (mean age 8.8 years, s.d. $=2.7$ ), risperidone (dose range $0.5-3.5 \mathrm{mg} /$ day, mean $1.8 \mathrm{mg} /$ day, s.d. $=0.7)$ was safe, well tolerated and efficacious for the treatment of tantrums, aggression and self-injurious behaviour (McCracken 2002). The primary outcome measures were the Irritability subscale scores of the Aberrant Behavior Checklist (ABC) and the Clinical Global Impressions Improvement (CGI-I) scale at 8 weeks. However, a follow-up study did not find significant improvement in core symptoms such as social interaction and communication as assessed by change in scores on the Children's Yale-Brown Obsessive Compulsive Scale, the Ritvo-Freeman Real Life Rating Scale and the Maladaptive Behaviour

\section{TABLE 1 Example of a medication decision-making schema for a child with autism spectrum disorder and comorbid disorders ${ }^{\mathrm{a}}$}

\begin{tabular}{|c|c|c|c|c|c|}
\hline Symptom & Methylphenidate & $\begin{array}{l}\text { Sodium } \\
\text { valproate }\end{array}$ & Aripiprazole & Sertraline & Evidence $^{b}$ \\
\hline Aggression & + & ++ & +++ & + & $\begin{array}{l}\text { Methylphenidate: might show some benefit but limited evidence } \\
\text { available for the treatment of aggression in children } \\
\text { Divalproex sodium: effect size of } 0.44 \text { for the ABC Irritability } \\
\text { subscale (Hollander 2010) } \\
\text { Aripiprazole: mean improvement of } 6.17 \text { points on the ABC } \\
\text { Irritability subscale and } 2.66 \text { points on the ABC Stereotypy subscale } \\
\text { (Ching 2012) } \\
\text { Sertraline: limited evidence for the treatment of aggression in } \\
\text { children }\end{array}$ \\
\hline $\begin{array}{l}\text { Inattention } \\
\text { Hyperactivity }\end{array}$ & $\begin{array}{l}+++ \\
++\end{array}$ & $\begin{array}{l}+ \\
+\end{array}$ & $\begin{array}{l}++ \\
++\end{array}$ & $\begin{array}{l}+/- \\
+/-\end{array}$ & $\begin{array}{l}\text { Methylphenidate: effect sizes of } 0.39 \text { and } 0.52 \text { for the parent and } \\
\text { teacher Conners ADHD index (Simonoff 2013). Effect sizes of } 0.49 \\
\text { on joint attention behaviours and } 0.29 \text { on self-regulation behaviours } \\
\text { in children when receiving their optimum dose of methylphenidate } \\
\text { compared with placebo (Jahromi 2009) } \\
\text { Sodium valproate: might show some benefits but evidence is scarce } \\
\text { Aripiprazole: mean improvement of } 7.93 \text { points on the ABC } \\
\text { Hyperactivity subscale (Ching 2012) } \\
\text { Sertraline: no study shows improvement in inattention and } \\
\text { hyperactivity }\end{array}$ \\
\hline $\begin{array}{l}\text { Anxiety } \\
\text { Depression }\end{array}$ & - & $\begin{array}{l}+/- \\
+/-\end{array}$ & $\begin{array}{l}+ \\
+\end{array}$ & $\begin{array}{c}+++ \\
++\end{array}$ & $\begin{array}{l}\text { Methylphenidate: unlikely to be beneficial } \\
\text { Sodium valproate: limited data available - no improvements } \\
\text { Aripiprazole: may produce some improvement in low doses } \\
\text { Sertraline: not specifically assessed in ASD but has shown to be } \\
\text { beneficial for treating childhood anxiety (effect size of } 0.45 \text { on the } \\
\text { Paediatric Anxiety Rating Scale) (Walkup 2008) }\end{array}$ \\
\hline Mood lability & + & +++ & ++ & - & $\begin{array}{l}\text { Methylphenidate: effect sizes of } 0.29 \text { on self-regulation behaviours } \\
\text { (Jahromi 2009) } \\
\text { Divalproex sodium: effect size of } 0.44 \text { for the ABC Irritability } \\
\text { subscale (Hollander 2010) } \\
\text { Aripiprazole: improves mood dysregulation - effect size of } 0.57 \\
\text { (aripiprazole v. placebo) for hazard ratio results from Kaplan-Meier } \\
\text { curves (Findling 2014) } \\
\text { Sertraline: unlikely to show improvement }\end{array}$ \\
\hline
\end{tabular}

ABC, Aberrant Behavior Checklist; ADHD, attention-deficit hyperactivity disorder; ASD, autism spectrum disorder

a. Comorbidities include ADHD, oppositional defiant disorder, generalised anxiety disorder, depression and mood lability.

b. Described in this article.

+++ , may produce significant improvement; ++ , may produce good improvement; + , may produce some improvement; $+/-$, no improvement; - , unlikely to be beneficial. 
domain of the Vineland Adaptive Behavior Scales (McDougle 2005).

In another study, based on ratings on the Childhood Autism Rating Scale (CARS) and Children's Global Assessment Scale (CGAS), risperidone was effective in improving global functioning and social responsiveness, and lessening hyperactivity and aggression in children with autism as young as 2 years of age (Nagaraj 2006).

A Cochrane review (Jesner 2007) showed some evidence of the benefits of risperidone in treating irritability, repetitive behaviours and social withdrawal in ASD. The authors stressed, however, that the findings from the review should be treated with caution as small sample sizes and the lack of a standardised outcome measure preclude the making of meaningful inferences.

\section{Aripiprazole}

Aripiprazole at dose ranges of $5-15 \mathrm{mg} /$ day for 8 weeks has been reported to be efficacious, safe and well tolerated for treating irritability in children and adolescents with autism who were presenting with tantrums, aggression or self-injurious behaviour (Marcus 2009; Owen 2009).

A Cochrane review (Ching 2012) showed a mean improvement of 6.17 points on the ABC irritability subscale, 7.93 points on the hyperactivity subscale and 2.66 points on the stereotypy subscale in children administered aripiprazole in comparison to those on placebo. The authors also noted that lengthier studies are warranted to garner information on safety, tolerability and efficacy of aripiprazole in the long term.

More recently, Findling et al (2014) evaluated the safety and efficacy of aripiprazole compared with placebo in preventing relapse of irritability associated with ASD in 85 patients (41 on aripiprazole, 44 on placebo) aged $6-17$ years old. In this relapse-prevention trial, the difference between aripiprazole and placebo in time to relapse was not statistically significant during maintenance treatment. However, during maintenance therapy some secondary efficacy measures were statistically significant in comparison with placebo for patients treated with aripiprazole.

\section{Risperidone and aripiprazole}

Both risperidone and aripiprazole have been approved by the US Food and Drug Administration to treat irritability associated with ASD. However, as far as we are aware, only one study has been published that makes a direct head-to-head comparison between the two drugs (Ghanizadeh 2014). It used change in ABC scores as the primary outcome measure, and the findings showed that the efficacy, along with the safety and tolerability profiles, of aripiprazole and risperidone were comparable.

\section{Other atypical antipsychotics}

An 8-week, double-blind placebo-controlled trial of olanzapine, involving eight patients diagnosed with PDD, six with autism, one with Asperger syndrome and four with PDD NOS, showed a $50 \%$ response in CGI-I score with olanzapine in comparison to placebo (20\% of responders) (Hollander 2006a).

Studies using quetiapine (Hardan 2005; Golubchik 2011), ziprasidone (Dominick 2015) and clozapine (Zuddas 1996; Gobbi 2001) have shown some promise in improving irritability and hyperactivity. However, these findings should be treated with caution as small sample sizes and open-label design preclude definitive inferences from being made. More work is needed to demonstrate the efficacy of these drugs in the clinical environment.

\section{Metabolic syndrome}

There is a strong correlation between metabolic syndrome (weight gain, dyslipidaemia and type II diabetes) and the use of antipsychotics in young people (Newcomer 2005). Almandil et al (2013) showed that olanzapine, risperidone and aripiprazole were all associated with weight gain in children and adolescents. Moreover, Bobo et al (2013) indicated that children and adolescents prescribed antipsychotics had a threefold increased risk for type II diabetes. As the safety and tolerability profile of each atypical antipsychotic is specific, it is recommended that adverse events associated with metabolic syndrome should be carefully monitored to inform treatment strategies. Despite this, to date there are no clinically validated monitoring mechanisms in place. Internet-based monitoring of sideeffects and remote physiological monitoring of cardiac function using wearable technology needs exploration because of the long-term negative impact of psychotropic-induced weight gain and metabolic syndrome.

\section{Benzodiazepines}

Owing to their propensity to induce tolerance and the adverse events associated with them, benzodiazepines are not recommended for the management of ASD, especially over the long term. They are sometimes used in acute situations to calm aggression, but disinhibition can occur, which can exacerbate the symptoms (Santosh 2014). 


\section{Treatment for inattention and hyperactivity}

Although ASD presents with myriad symptoms, inattention and hyperactivity are frequently encountered in children with the disorder and often warrant a diagnosis of ADHD (Santosh 2012; Lee 2014). Refer to the review by Santosh \& Colonneli (2012) for detailed information on the comorbidity of ASD and ADHD and its treatments.

\section{Methylphenidate}

A large open-label clinical study comparing stimulant treatment (mainly methylphenidate) of a group of children and adolescents with ADHD and a group with ADHD comorbid with ASD found good symptom reduction in both groups (Santosh 2006). In a large double-blind placebocontrolled trial (122 children aged 7-15 years with intellectual disability and hyperactivity) that used the parent/teacher ADHD index of the Conners Rating Scale - Short Version at 16 weeks as the primary outcome measure, optimal dosing with methylphenidate was effective in some children (Simonoff 2013).

A secondary analysis of RUPP Autism Network data showed that methylphenidate had positive outcomes in social communication and self-regulation in 33 children with PDD and hyperactivity (29 boys and 4 girls, aged 5-13 years) (Jahromi 2009). These data suggest that methylphenidate dosing is related to changes in joint attention (modulating social behaviours), with lower doses being better than higher doses. It is likely that higher doses are necessary if the target is hyperactivity.

\section{Amphetamines}

Amphetamines have been used for the treatment of ADHD in children; however, there are no published studies on the efficacy of amphetamines in children and adolescents with ASD. Lisdexamfetamine dimesylate is a therapeutically inactive pro-drug comprising of $d$-amphetamine bound to the amino acid lysine. Using the investigator-rated ADHD Rating Scale IV (ADHD-RS-IV) as the primary outcome measure, lisdexamfetamine dimesylate was efficacious for the treatment of ADHD in children and adolescents aged $6-17$ years and was well tolerated (Coghill 2013). Lisdexamfetamine dimesylate may be an agent that could be considered for managing ADHD in ASD.

\section{Atomoxetine}

In a comprehensive review examining the effects of atomoxetine in young people with developmental disabilities, Aman et al (2014) reported a positive outcome of atomoxetine on ADHD in all ten studies that were evaluated. However, only two of these were randomised double-blind placebocontrolled trials that focused on children with ASD. One (Arnold 2006) had a small sample $(n=16)$, and although the other (Harfterkamp 2012) had a much larger sample $(n=102)$, it used only parent and clinician ratings as outcome indicators (Aman 2014).

Using parent-based outcome measures (the $\mathrm{ABC}$ and the Children's Social Behaviour Questionnaire (CSBQ)), a randomised double-blind placebo-controlled 8-week trial in 97 patients with ASD and ADHD recently showed that atomoxetine had no effect on core ASD symptoms (Harfterkamp 2014). More recently, another study showed no evidence for predictors of response to atomoxetine in children and adolescents with ASD and ADHD symptoms (Harfterkamp 2015).

\section{Alpha-2 adrenergic receptor agonists}

Clonidine and guanfacine are alpha-2 adrenergic agonists that have shown some promise in treating ADHD in ASD. In one double-blind placebo crossover study involving nine males with autism aged 5-33 years, transdermal clonidine was effective in ameliorating hyperactivity (Fankhauser 1992). However, others have argued that clonidine is unlikely to be of benefit for the treatment of ADHD in individuals with ASD (Hazell 2007). Sedation is a frequent adverse effect of clonidine and, in comparison, guanfacine might have a better safety and tolerability profile. Guanfacine is thought to be less sedating and its half-life is longer $(10-30 \mathrm{~h})$ than that of clonidine (4-10 h), which might lead to an easier dosing regimen. Open-label studies suggest some improvements in hyperactivity and impulsiveness and, to a lesser extent, in teacherreported outcomes (Scahill 2006). More recently, in a multisite randomised placebo controlled trial involving 62 children with ASD (mean age of 8.5 years), extended-release guanfacine was shown to be safe, well-tolerated and efficacious in lowering hyperactivity, distractibility and impulsivity (Scahill 2015).

\section{Treatment for anxiety and depression}

Anxiety disorders frequently present in children and adolescents with ASD, with comorbidity ranges of $40-84 \%$ for any anxiety disorder, 8-63\% for specific phobias, 5-23\% for generalised anxiety, $13-29 \%$ for social anxiety and 8-27\% for separation anxiety (Sukhodolsky 2013). The usual treatment for anxiety in ASD involves selective serotonin reuptake inhibitors (SSRIs), including sertraline, fluoxetine, fluvoxamine and citalopram. 
These SSRIs have all demonstrated efficacy in children with anxiety disorder and, although they have not specifically assessed in ASD, sertraline together with cognitive-behavioural therapy has proved beneficial for the treatment of childhood anxiety (Walkup 2008).

Another agent that has targeted anxiety in children with ASD and shows some effectiveness is buspirone (Buitelaar 1998). More recently, the classical beta-adrenergic antagonist propranolol has shown positive cognitive effects in the brains of adults with ASD (Narayanan 2010); however, more work is needed to properly evaluate its use for the treatment of anxiety in children with ASD.

There is limited evidence for the effectiveness of SSRIs as a treatment for depression in children with ASD (Williams 2013). However, the use of fluoxetine can be warranted in a child with ASD who is severely depressed (Santosh 2014). In general, clinical decision-making regarding the treatment of depression in children and adolescents with ASD should be made on a case-by-case basis.

\section{Treatment for sleep disorders}

Sleep disorders are common in children with ASD. Between 40 and $80 \%$ of children experience some type of sleep disorder in comparison with $25-40 \%$ in typically developing children. The most common sleep disorders are insomnia, reduced sleep efficiency, bedtime resistance and daytime sleepiness. A comprehensive metaanalysis evaluating melatonin in the treatment of sleep disorders in ASD (Rossignol 2011) showed that it was well tolerated and might improve sleep parameters and daytime behaviours.

A randomised placebo-controlled Phase III trial evaluated the efficacy of melatonin for sleep problems in 146 children (age 3-15.8 years) with neurodevelopmental disorders (Gringras 2012). Using total sleep time at night after 12 weeks (adjusted for baseline) recorded in sleep diaries by parents as the main outcome measure, it showed some improvements in the child's sleep with melatonin (i.e. children fell asleep more quickly), but the child's behaviour and family functioning measures did not significantly improve.

\section{Treatment of mood lability and bipolar disorder}

Anti-epileptic drugs are used for bipolar disorder and mood lability in children with ASD, and they have also been prescribed for impulsivity, irritability, aggressive behaviour and rage. In a randomised double-blind placebo-controlled trial evaluating the efficacy of divalproex sodium for the treatment of irritability in 55 children with ASD using the $\mathrm{ABC}$ and CGI-I Irritability subscales as primary outcome measures, statistically significant improvements in irritability and aggression were reported (Hollander 2010). Other evidence suggests that aripiprazole and risperidone are beneficial in improving mood dysregulation (McCracken 2002; Findling 2014).

\section{Treatment of social disability, repetitive behaviours and self-injurious behaviour}

\section{Social disability}

An overview of the treatment of social disability is presented elsewhere (Santosh 2014). One way in which social disability can be measured in children with ASD is by using the parent-rated Social Withdrawal subscale of the ABC. This subscale monitors social disability by capturing recognisable behaviours in response to interaction instigated by others and the degree to which the child begins the interaction (Scahill 2013). In a secondary analysis on ABC Social Withdrawal subscale data from two multicentre trials, it was proposed that after 8 weeks of treatment, risperidone was effective for the treatment of social disability in children with ASD (Scahill 2013).

\section{Repetitive behaviours and circumscribed interests}

Although some studies have suggested that SSRIs might help in ameliorating repetitive behaviours and circumscribed interests in children and adolescents with ASD, a Cochrane review examining nine randomised controlled trials with a total of 320 participants showed that there was no evidence to demonstrate that SSRIs (fluoxetine, fluvoxamine, fenfluramine or citalopram) were beneficial in comparison to placebo (Williams 2013). SSRIs can often cause behavioural activation when used in ASD.

In an 8-week double-blind placebo-controlled trial, Hollander et al (2006b) showed that divalproex sodium might be beneficial in improving repetitive behaviours in individuals with ASD.

\section{Self-injurious behaviour}

Self-injurious behaviour presents one of the most challenging behavioural disorders in ASD and is particularly distressing for parents. Such behaviour can include, but is not limited to, hand biting, hitting the head against objects or hands, and skin scratching.

It has been reported that risperidone is effective in targeting self-injurious behaviour, especially in severe cases (McCracken 2002). Opioid antagonists such as naltrexone have 
been used for the management of self-injurious behaviour based on the premise that there is an abnormality in pain control in individuals with ASD with these behaviours. Although open-label studies suggest that naltrexone might be beneficial for children with self-injurious behaviour and autism (Elchaar 2006), double-blind placebocontrolled clinical trials found it to be no different than placebo for managing these behaviours (Willemsen-Swinkels 1995).

A summary of the common comorbidities in ASD and their treatment is presented in Table 2.

\section{Disorder-modifying treatments}

Comorbidity associated with ASD frequently compounds the treatment of core symptoms observed in the disorder. Hitherto no validated pharmacological interventions that directly aim to ameliorate the core social and communication defects of ASD have been available. In recent years a paradigm shift in the understanding of the pathophysiology of ASD has allowed new candidates to be identified that have the potential to act as disorder-modifying agents. The pertinent observations are described in this section.

\section{Sulforaphane}

Sulforaphane, a compound found in cruciferous vegetables, up-regulates antioxidant genes involved in control mechanisms through the Keap1-Nrf2 cytoprotective signalling pathway. This leads to modulation of oxidative stress, antioxidant capacity and neuroinflammation. Sulforaphane has recently been evaluated in a randomised double-blind placebo-controlled trial involving young males ( $n=44 ; 29$ on active treatment, 15 on placebo) aged 13-27 years with moderate to severe ASD (Singh 2014). This showed that patients receiving daily doses of 50-150 $\mu$ mol sulforaphane for 18 weeks had statistically significant improvements in social interaction, irritability, hyperactivity and verbal communication scores in comparison with patients receiving placebo (as assessed by change on ABC Irritability subscale, Social Responsiveness Scale (SRS) and CGI-I scores). Further evaluation in larger-scale clinical trials will be required to confirm the efficacy of sulforaphane in ASD.

\section{Oxytocin}

Oxytocin is a hormone comprising nine amino acids made in the hypothalamus and secreted

TABLE 2 Common comorbidities in autism spectrum disorder and their treatment ${ }^{\mathrm{a}}$

\begin{tabular}{|c|c|c|c|}
\hline Comorbidity & Symptom focus & Severity & Treatment \\
\hline \multicolumn{4}{|l|}{ Mood and anxiety } \\
\hline Depression & Irritability, negative cognitions & Moderate/severe & mCBT and fluoxetine \\
\hline \multirow[t]{2}{*}{ Anxiety disorder } & $\begin{array}{l}\text { Anticipatory anxiety, fear, phobia, panic } \\
\text { attacks }\end{array}$ & Moderate & mCBT and buspirone \\
\hline & $\begin{array}{l}\text { Anticipatory anxiety, fear, phobia, panic } \\
\text { attacks }\end{array}$ & Severe & $\begin{array}{l}\text { mCBT and an SSRI (e.g. sertraline, fluoxetine, } \\
\text { citalopram) }\end{array}$ \\
\hline Anxiety disorder & $\begin{array}{l}\text { Autonomic arousal, hypersensitivity to } \\
\text { tachycardia, panic attacks }\end{array}$ & Severe & mCBT and propranolol \\
\hline Insomnia & Anxiety related & Moderate/severe & $\begin{array}{l}\text { mCBT and sleep hygiene, sertraline, } \\
\text { mirtazapine }\end{array}$ \\
\hline Insomnia & Primary & Moderate/severe & $\begin{array}{l}\text { Sleep hygiene, melatonin, clonidine, } \\
\text { mirtazapine, trazodone, gabapentin }\end{array}$ \\
\hline \multicolumn{4}{|l|}{ Attention deficit/hyperactivity } \\
\hline Attention-deficit disorder & Inattention & Severe & Methylphenidate, dexamfetamine \\
\hline Attention-deficit hyperactivity disorder & Hyperactivity, impulsivity & Moderate & $\begin{array}{l}\text { Methylphenidate, dexamfetamine, } \\
\text { atomoxetine, clonidine/guanfacine }\end{array}$ \\
\hline Attention-deficit hyperactivity disorder & Hyperactivity, impulsivity & Severe & $\begin{array}{l}\text { Methylphenidate, dexamfetamine, } \\
\text { atomoxetine, aripiprazole/risperidone }\end{array}$ \\
\hline \multicolumn{4}{|l|}{ Irritability, aggression and agitation } \\
\hline $\begin{array}{l}\text { Oppositional defiant disorder and } \\
\text { disruptive mood dysregulation disorder }\end{array}$ & Irritability, aggression, agitation & Moderate & $\begin{array}{l}\text { mCBT and sodium valproate, } \\
\text { methylphenidate/dexamfetamine, } \\
\text { atomoxetine, clonidine/guanfacine, } \\
\mathrm{N} \text {-acetylcysteine }\end{array}$ \\
\hline $\begin{array}{l}\text { Oppositional defiant disorder and } \\
\text { disruptive mood dysregulation disorder }\end{array}$ & Irritability, aggression, agitation & Severe & Aripiprazole/risperidone \\
\hline
\end{tabular}

mCBT, modified cognitive-behavioural therapy; SSRIs, selective serotonin reuptake inhibitors.

a. Note that the evidence base is limited. 
from the posterior pituitary gland. It has been surmised that oxytocin plays a key role in social affiliation and attachment, and that variation in the oxytocin receptor gene might be responsible for ASD (Wermter 2010). A randomised double-blind placebo-controlled trial evaluating the efficacy of intranasal oxytocin, using change in caregivercompleted SRS and clinician-rated CGI-I scores as primary outcome measures in 50 males with ASD aged 12-18 years, showed that the primary and secondary efficacy outcome measures in active treatment $(n=26)$ were no different to placebo $(n=24)$ (Guastella 2015).

In another randomised double-blind placebocontrolled trial, intranasal oxytocin (24 international units (IU), administered on two visits separated by 1 week) was tested on 32 adult males with ASD and 32 placebo controls using Tobii eye tracking to determine whether it could improve eye gaze behaviour, a key marker for social communication difficulties in ASD (Auyeung 2015). This study showed that intranasal oxytocin increased eye gaze behaviour in both the autism and placebo groups, with patients in the autism group who spent less time looking to the eye region benefiting most from intranasal oxytocin treatment.

\section{$N$-acetylcysteine}

$N$-acetylcysteine is a prodrug of L-cysteine and following oral administration is rapidly absorbed. Subsequently, the uptake of cystine results in the shuttling of glutamate out of the cell and is therefore pivotal in the regulation of extracellular glutamate levels. This is important because it has been recognised that dysregulation of glutamatergic neurotransmission and glutathione synthesis might be causative factors in ASD. A randomised placebo-controlled trial has provided evidence for the efficacy of $\mathrm{N}$-acetylcysteine in treating irritability in children with autism (Hardan 2012). Recently, a randomised double-blind placebocontrolled trial has shown that $N$-acetylcysteine is an effective adjunct to risperidone for the treatment of irritability in children 4-12 years of age with autism (Nikoo 2015). Although promising, further work is required to determine a role for $\mathrm{N}$-acetylcysteine in the treatment of ASD.

\section{D-cycloserine}

Originally known for its use as an effective antibiotic for the treatment of pulmonary tuberculosis (Walker 1957), D-cycloserine has gained attention for its potential use as a treatment in psychiatric disorders (Schade 2015). D-cycloserine is a glycine partial agonist at the $N$-methyl-D-aspartate (NMDA) receptor, and a pilot study of its use showed significant improvements in social withdrawal in individuals with autism (Posey 2004). More recently, others have observed positive effects of D-cycloserine on stereotypies (Urbano 2014) and social deficits (Urbano 2015) in individuals 14-25 years old with ASD. These data suggest that D-cycloserine might be useful in ameliorating core deficits of ASD; however, larger double-blind placebo-controlled studies would be required to further develop and expand on these results.

\section{Insulin growth factor 1}

It has been hypothesised that brain development is altered in ASD, and crucially insulin growth factor 1 (IGF-1) is important for brain development. Elevated levels of IGF-1 and other growth factors have been found in boys with ASD (Mills 2007). Recently, a Phase I study evaluating the safety, pharmacokinetics and efficacy of recombinant human IGF-1 (mecasermin) in 12 girls aged 2-10 years with Rett syndrome showed a mixed clinical picture. SPreliminary efficacy evaluations on neurobehavioral parameters produced a mixed picture: on some measures some girls showed improvements, whereas others showed deterioration (Khwaja 2014). Further work is warranted to evaluate the efficacy of IGF-1 in children with Rett syndrome.

\section{Complementary and alternative medicines}

Studies on complementary and alternative medicines (CAMs) for the treatment of ASD and its comorbidities lack empirical scientific evidence and therefore limited information is available to ascertain whether they have any impact on the comorbidities associated with ASD. Levy $\&$ Hyman (2008) have suggested that $50-70 \%$ of children with ASD in treatment studies receive CAMs. Frequently used therapies include chelating agents, vitamins and essential fatty acids.

Many children with autism have received chelation therapy, but there is considerable circumspection with regard to its efficacy in ASD (Brent 2013). Patients given chelation therapy can experience serious adverse events, and previously the US Food and Drug Administration has indicated that promoting the use of over-thecounter chelation products for the treatment of autism and other conditions was deemed to be unsafe and illegal (Voelker 2010).

Perhaps the most widely used CAMs are vitamin supplements and essential fatty acids. One review reports that at present there is no evidence to indicate a role for omega-3 fatty acids in the treatment of autism (Williams 2012). 


\section{Future perspectives}

The ultimate goal of drug intervention in ASD is to improve the quality of life of patients by targeting the core symptoms of the disorder, rather than just its comorbidities. As far as we are aware, there is no evidence to indicate a treatment strategy that has a long-lasting impact on ASD and brings about recovery. Although research efforts to develop agents to ameliorate the core symptoms of ASD have intensified in recent years, these studies are limited in their sample size and much larger clinical trials of sufficient power are warranted to tease out the pertinent information. In the meantime, comprehensive treatment programmes such as psychosocial, language and behavioural therapies, coupled with drug treatments with careful monitoring of symptoms and adverse events, allow clinicians and healthcare workers in child and adolescent mental health services to make significant improvements in the quality of life of young people with ASD.

\section{References}

Almandil NB, Liu Y, Murray ML, et al (2013) Weight gain and other metabolic adverse effects associated with atypical antipsychotic treatment of children and adolescents: a systematic review and metaanalysis. Paediatic Drugs, 15: 139-50.

Altamura AC, Moro AR, Percudani M (1994) Clinical pharmacokinetics of fluoxetine. Clinical Pharmacokinetics, 26: 201-14.

Aman MG, Smith T, Arnold LE, et al (2014) A review of atomoxetine effects in young people with developmental disabilities. Research in Developmental Disabilities, 35: 1412-24.

American Psychiatric Association (2013) Diagnostic and Statistical Manual of Mental Disorders, Fifth Edition (DSM-5). APA

Arnold LE, Aman MG, Cook AM, et al (2006) Atomoxetine for hyperactivity in autism spectrum disorders: placebo-controlled crossover pilot trial. Journal of the American Academy of Child and Adolescent Psychiatry, 45: 1196-205.

Auyeung B, Lombardo MV, Heinrichs M, et al (2015) Oxytocin increases eye contact during a real-time, naturalistic social interaction in males with and without autism. Translational Psychiatry, 5: e507.

Bobo WV, Cooper WO, Stein CM, et al (2013) Antipsychotics and the risk of type 2 diabetes mellitus in children and youth. JAMA PSychiatry, 70 : 1067-75.

Brent $\mathrm{J}$ (2013) Commentary on the abuse of metal chelation therapy in patients with autism spectrum disorders. Journal of Medical Toxicology, 9: 370-2.

Buitelaar JK, van der Gaag RJ, van der Hoeven J (1998) Buspirone in the management of anxiety and irritability in children with pervasive developmental disorders: results of an open-label study. Journal of Clinical Psychiatry, 59: 56-9.

Ching H, Pringsheim T (2012) Aripiprazole for autism spectrum disorders (ASD). Cochrane Database of Systematic Reviews, 5: CD009043.

Coghill D, Banaschewski T, Lecendreux M, et al (2013) European, randomized, phase 3 study of lisdexamfetamine dimesylate in children and adolescents with attention-deficit/hyperactivity disorder. European Neuropsychopharmacology, 23: 1208-18.

Dominick K, Wink LK, McDougle CJ, et al (2015) A retrospective naturalistic study of ziprasidone for irritability in youth with autism spectrum disorder. Journal of Child and Adolescent Psychopharmacology, 25: 397-401.
Elchaar GM, Maisch NM, Augusto LM (2006) Efficacy and safety of naltrexone use in pediatric patients with autistic disorder. Annals of Pharmacotherapy, 40: 1086-95.

Fankhauser MP, Karumanchi VC, German ML, et al (1992) A double blind, placebo-controlled study of the efficacy of transdermal clonidine in autism. Journal of Clinical Psychiatry, 53: 77-82.

Findling RL, Mankoski R, Timko K, et al (2014) A randomized controlled trial investigating the safety and efficacy of aripiprazole in the long-term maintenance treatment of pediatric patients with irritability associated with autistic disorder. Journal of Clinical Psychiatry, 75: 22-30.

Ghanizadeh A, Sahraeizadeh A, Berk M (2014) A head-to-head comparison of aripiprazole and risperidone for safety and treating autistic disorders, a randomized double blind clinical trial. Child Psychiatry and Human Development, 45: 185-92.

Gobbi G, Pulvirenti L (2001) Long-term treatment with clozapine in an adult with autistic disorder accompanied by aggressive behaviour. Journal of Psychiatry \& Neuroscience, 26: 340-1.

Golubchik P, Sever J, Weizman A (2011) Low-dose quetiapine for adolescents with autistic spectrum disorder and aggressive behavior: open-label trial. Clinical Neuropharmacology, 34: 216-9.

Gringras P, Gamble C, Jones AP, et al (2012) Melatonin for sleep problems in children with neurodevelopmental disorders: randomised double masked placebo controlled trial. BMJ, 345: e6664.

Guastella AJ, Gray KM, Rinehart NJ, et al (2015) The effects of a course of intranasal oxytocin on social behaviors in youth diagnosed with autism spectrum disorders: a randomized controlled trial. Journal of Child Psychology and Psychiatry, 56: 444-52.

Hardan AY, Jou RJ, Handen BL (2005) Retrospective study of quetiapine in children and adolescents with pervasive developmental disorders. Journal of Autism Development Disorders, 35: 387-91.

Hardan AY, Fung LK, Libove RA, et al (2012) A randomized controlled pilot trial of oral $\mathrm{N}$-acetylcysteine in children with autism. Biological Psychiatry, 71: 956-61.

Harfterkamp M, van de Loo-Neus G, Minderaa RB, et al (2012) A randomized double-blind study of atomoxetine versus placebo for attention-deficit/hyperactivity disorder symptoms in children with autism spectrum disorder. Journal of the American Academy of Child and Adolescent Psychiatry, 51: 733-41.

Harfterkamp M, Buitelaar JK, Minderaa RB, et al (2014) Atomoxetine in autism spectrum disorder: no effects on social functioning; some beneficial effects on stereotyped behaviors, inappropriate speech, and fear of change. Journal of Child and Adolescent Psychopharmacology, 24: 481-5.

Harfterkamp M, van der Meer D, van der Loo-Neus G, et al (2015) No evidence for predictors of response to atomoxetine treatment of attentiondeficit/hyperactivity disorder symptoms in children and adolescents with autism spectrum disorder. Journal of Child and Adolescent Psychopharmacology, 25: 372-5

Hazell P (2007) Drug therapy for attention-deficit/hyperactivity disorderlike symptoms in autistic disorder. Journal of Paediatrics and Child Health, 43: 19-24.

Hill AP, Zuckerman K, Fombonne E (2014) Epidemiology of autism spectrum disorders. In Handbook of Autism and Pervasive Developmental Disorders (4th edn) (eds Volkmar FR, Paul R, Rogers SJ, et al): 57-96. Wiley.

Hollander E, Wasserman S, Swanson EN, et al (2006a) A double-blind placebo-controlled pilot study of olanzapine in childhood/adolescent pervasive developmental disorder. Journal of Child and Adolescent Psychopharmacology, 16: 541-8

Hollander E, Soorya L, Wasserman S, et al (2006b) Divalproex sodium vs. placebo in the treatment of repetitive behaviours in autism spectrum disorder. International Journal of Neuropsychopharmacology, 9: 209-13

Hollander E, Chaplin W, Soorya L, et al (2010) Divalproex sodium vs placebo for the treatment of irritability in children and adolescents with autism spectrum disorders. Neuropsychopharmacology, 35: 990-8. 


\section{MCQ answers \\ 1 e $\quad 2$ b 3 c $\quad 4$ b 5 e}

Jahromi LB, Kasari CL, McCracken JT, et al (2009) Positive effects of methylphenidate on social communication and self-regulation in children with pervasive developmental disorders and hyperactivity. Journal of Autism and Developmental Disorders, 39: 395-404.

Jesner OS, Aref-Adib M, Coren E (2007) Risperidone for autism spectrum disorder. Cochrane Database of Systematic Reviews, 1: CD005040.

Khwaja OS, Ho E, Barnes KV, et al (2014) Safety, pharmacokinetics, and preliminary assessment of efficacy of mecasermin (recombinant human IGF-1) for the treatment of Rett syndrome. Proceedings of the National Academy of Sciences of the United States of America, 111: 4596-601.

Lee YJ, Oh SH, Park C, et al (2014) Advanced pharmacotherapy evidenced by pathogenesis of autism spectrum disorder. Clinical Psychopharmacology and Neuroscience, 12: 19-30.

Levy SE, Hyman SL (2008) Complementary and alternative medicine treatments for children with autism spectrum disorders. Child and Adolescent Psychiatric Clinics of North America, 17: 803-20.

Marcus RN, Owen R, Kamen L, et al (2009) A placebo-controlled, fixeddose study of aripiprazole in children and adolescents with irritability associated with autistic disorder. Journal of the American Academy of Child and Adolescent Psychiatry, 48: 1110-9.

McCracken JT, McGough J, Shah B, et al (2002) Risperidone in children with autism and serious behavioural problems. New England Journal of Medicine, 347: 314-21.

McDougle CJ, Scahill L, Aman MG, et al (2005) Risperidone for the core symptom domains of autism: results from the study by the autism network of the research units on pediatric psychopharmacology. American Journal of Psychiatry, 162: 1142-8.

Mills JL, Hediger ML, Molloy CA, et al (2007) Elevated levels of growthrelated hormones in autism and autism spectrum disorder. Clinical Endocrinology (0xford), 67: 230-7.

Nagaraj R, Singhi P, Malhi P (2006) Risperidone in children with autism: randomized, placebo-controlled, double-blind study. Journal of Child Neurology, 21: 450-5.

Narayanan A, White CA, Saklayen S, et al (2010) Effect of propranolol on functional connectivity in autism spectrum disorder - a pilot study. Brain Imaging and Behaviour, 4: 189-97.

National Institute for Health and Care Excellence (2011) Autism Diagnosis in Children and Young People: Recognition, Referral and Diagnosis of Children and Young People on the Autism Spectrum (Clinical Guideline GG128). NICE.

National Institute for Health and Care Excellence (2013) Autism: The Management and Support of Children and Young People on the Autism Spectrum (Clinical Guideline GG170). NICE.

Newcomer JW (2005) Second-generation (atypical) antipsychotics and metabolic effects: a comprehensive literature review. CNS Drugs, 19 (suppl 1): 1-93.

Nikoo M, Radnia H, Farokhnia M, et al (2015) N-acetylcysteine as an adjunctive therapy to risperidone for treatment of irritability in autism: a randomized, double-blind, placebo-controlled clinical trial of efficacy and safety. Clinical Neuropharmacology, 38: 11-7.

Owen R, Sikich L, Marcus RN, et al (2009) Aripiprazole in the treatment of irritability in children and adolescents with autistic disorder. Pediatrics, 124: $1533-40$.

Posey DJ, Kem DL, Swiezy NB, et al (2004) A pilot study of D-cycloserine in subjects with autistic disorder. American Journal of Psychiatry, 161: 2115-7.

Rossignol DA, Frye RE (2011) Melatonin in autism spectrum disorders: a systematic review and meta-analysis. Developmental Medicine and Child Neurology, 53: 783-92.

Sandin S, Lichtenstein P, Kuja-Halkola R, et al (2014) The familial risk of autism. JAMA, 311: 1770-7.

Santosh PJ, Baird G, Pityaratstian N, et al (2006) Impact of comorbid autism spectrum disorders on stimulant response in children with attention deficit hyperactivity disorder: a retrospective and prospective effectiveness study. Child: Care, Health and Development, 32: 575-83.
Santosh PJ, Colonneli C (2012) Co-occurrence of attention deficit hyperactivity disorder (ADHD) and autism spectrum disorders (ASD). Cutting Edge Psychiatry in Practice, 2: 118-26.

Santosh PJ (2014) Medication in autism spectrum disorder. Cutting Edge Psychiatry in Practice, 4: 143-55.

Scahill L, Aman MG, McDougle CJ, et al (2006) A prospective open trial of guanfacine in children with pervasive developmental disorders. Journal of Child and Adolescent Psychopharmacology, 16: 589-98.

Scahill L, Hallett V, Aman MG, et al (2013) Brief Report: social disability in autism spectrum disorder: results from Research Units on Pediatric Psychopharmacology (RUPP) Autism Network trials. Journal of Autism and Developmental Disorders, 43: 739-46.

Scahill L, McCracken JT, King BH, et al (2015) Extended-release guanfacine for hyperactivity in children with autism spectrum disorder. American Journal of Psychiatry, 172: 1197-206.

Schade S, Paulus W (2015) D-cycloserine in neuropsychiatric diseases: a systematic review. International Journal of Neuropsychopharmacology, 12 Sept: doi 10.1093/ijnp/pyv102 [Epub ahead of print]

Simonoff E, Pickles A, Charman T, et al (2008) Psychiatric disorders in children with autism spectrum disorders: prevalence, comorbidity, and associated factors in a population-derived sample. Journal of the American Academy of Child and Adolescent Psychiatry, 47: 921-9.

Simonoff E, Taylor E, Baird G, et al (2013) Randomized controlled double-blind trial of optimal dose methylphenidate in children and adolescents with severe attention deficit hyperactivity disorder and intellectual disability. Journal of Child Psychology and Psychiatry, 54: 527-35

Singh K, Connors SL, Macklin EA, et al (2014) Sulforaphane treatment of autism spectrum disorder (ASD). Proceedings of the National Academy of Sciences of the United States of America, 111: 15550-5.

Sukhodolsky DG, Bloch MH, Panza KE, et al (2013) Cognitive-behavioural therapy for anxiety in children with high-functioning autism: a metaanalysis. Pediatrics 132: e1341-50.

Urbano M, Okwara L, Manser P, et al (2014) A trial of D-cycloserine to treat stereotypies in older adolescents and young adults with autism spectrum disorder. Clinical Neuropharmacology, 37: 69-72.

Urbano M, Okwara L, Manser $\mathrm{P}$, et al (2015) A trial of d-cycloserine to treat the social deficit in older adolescents and young adults with autism spectrum disorders. Journal of Neuropsychiatry and Clinical Neurosciences, 27: 133-8.

Voelker $\mathrm{R}$ (2010) FDA warning targets OTC chelation products. JAMA, 304: 2112

Walker WC, Murdoch JM (1957) Cycloserine in the treatment of pulmonary tuberculosis: a report on toxicity. Tubercle, 38: 297-302.

Walkup JT, Albano AM, Piacentini J, et al (2008) Cognitive behavioral therapy, sertraline, or a combination in childhood anxiety. New England Journal of Medicine, 359: 2753-66.

Wermter AK, Kamp-Becker I, Hesse P (2010) Evidence for the involvement of genetic variation in the oxytocin receptor gene (OXTR) in the etiology of autistic disorders on high-functioning level. American Journal of Medical Genetics. Part B, Neuropsychiatric Genetics, 153B: 629-39.

Willemsen-Swinkels SH, Buitelaar JK, Nijhof GJ, et al (1995) Failure of naltrexone hydrochloride to reduce self-injurious and autistic behavior in mentally retarded adults. Double-blind placebo-controlled studies. Archives of General Psychiatry, 52: 766-73

Williams K, Marraffa C (2012) No evidence yet to support omega-3 fatty acids as a treatment for autism. Journal of Paediatrics and Child Health, 48: 534-6.

Williams K, Brignell A, Randall M, et al (2013) Selective serotonin reuptake inhibitors (SSRIs) for autism spectrum disorders (ASD). Cochrane Database of Systematic Reviews, 8: CD004677.

Zuddas A, Ledda MG, Fratta A, et al (1996) Clinical effects of clozapine on autistic disorder. American Journal of Psychiatry, 153: 738 
MCQs

Select the single best option for each question stem

1 The 2013 NICE evidence-based guidelines on the management and support of children and young people with ASD advise that:

a antipsychotics can be used to manage the core features of autism in children and young people

b antipsychotics and antidepressants can both be used to manage the symptoms of autism in children and young people

c exclusion diets (e.g. gluten- or casein-free diets) can be used to manage the core features of autism in children and young people

$\mathrm{d}$ antidepressants can be used to manage the repetitive behaviours and circumscribed interests of autism in children and young people

e antipsychotics, antidepressants, anticonvulsants or exclusion diets (e.g. glutenor casein-free diets) should not be used to manage the core features of autism in children and young people.

\section{SSRIs:}

a help to reduce mood lability in ASD

$\mathrm{b}$ are not useful in reducing repetitive behaviour and circumscribed interests in ASD

c have proven efficacy in managing anxiety in ASD

$d$ rarely produce behavioural activation in ASD

e frequently help reduce hyperactivity in ASD.

3 The best drug choice for treating severe aggression in children with ASD is:

a sodium valproate

b methylphenidate and sodium valproate

c aripiprazole

d methylphenidate

e sertraline.

4 The best drug choice for treating inattention, impulsivity and hyperactivity (ADHD) in children with ASD is:

a methylphenidate and aripiprazole

b methylphenidate or atomoxetine

c aripiprazole d sertraline

e sodium valproate.

5 A potential disorder-modifying agent for ASD is:

a clonidine

b risperidone

c aripiprazole

d fluoxetine

e $\mathrm{N}$-acetylcysteine. 